\title{
Suorakylvökoneen vantaan työsyvyyden mittaaminen
}

\author{
Timo Lötjönen, Pasi Suomi ja Hannu Mikkola
}

Maa- ja elintarviketalouden tutkimuskeskus, Maatalousteknologian tutkimus (Vakola)

Vakolantie 55,03400Vihti, timo.lotjonen@mtt.fi, pasi.suomi@mtt.fi, hannu.j.mikkola@mtt.fi

\section{Johdanto}

Viljojen tuottajahinnat ovat laskeneet puoleen siitä, mitä ne olivat ennen kuin Suomi liittyi Euroopan Unioniin. Vaikka osa tulonmenetyksistä onkin korvattu tuilla, on myös tuotantokustannuksia pyrittävä alentamaan. Viljojen suorakylvö on yksi mahdollisuus kustannusten leikkaamiseen. Etuna saattaa olla myös viljelyn parempi ympäristöystävällisyys perinteiseen, paljon muokkauksia sisältävään viljelytapaan nähden.

Suorakylvökoneissa siementen kylvösyvyys säädetään vantaissa olevien tukipyörien ja vantaiden painotuksen avulla. Säätö on ongelmallisempaa kuin esimerkiksi laahavannaskoneissa, joilla kylvö tapahtuu yleensä äkeellä tehdyn muokkauskerroksen ja muokkaamattoman maan rajapintaan. Oikealla kylvösyvyydellä on merkitystä: liian pintaan jääneet siemenet eivät idä ja liian syvälle kylvetyt siemenet eivät jaksa nousta pintaan saakka. Jos työsyvyyttä voidaan mitata tarkasti, voidaan myös vantaita kehittää niin, että ne kylvävät tarkasti oikeaan syvyyteen, vaikka pellon ominaisuudet vaihtelevatkin.

Yleinen menetelmä maatalouskoneiden työsyvyyden mittaamiseksi on mittasuksi tai -pyörä, joka seuraa maan pintaa. Tämän pinnan ja koneen rungon välinen etäisyys muutetaan sähköiseksi viestiksi lineaarisen potentiometrin tai LVDT-anturin avulla. Esimerkiksi Gebresenbet ja Jönsson (1992) ovat käyttäneet tätä menetelmää kylvökoneen laahavantaan työsyvyyden mittaamiseen ja Ahokas (1994) kyntöauran työsyvyyden mittaamiseen. Sögaard (1998) käytti ultraäänianturia mittaamaan mittapyörän korkeutta rikkakasviäkeen työsyvyysmittauksessa. Myöskin Arrivo ja Di Renzo (1998) sovelsivat samaa anturia kehittämässään testilaitteessa.

Muokatun maan pinnan Otason määrittäminen on kaikilla menetelmillä ongelma. Miten ottaa huomioon maakokkareet, olkikasat ja urat, joiden yli mittasuksi tai -pyörä voivat hypätä? Pehmeissä paikoissa mittaelimet voivat upota ja märkä maa voi tarttua kiinni niihin.

Välttääkseen nämä ongelmat eräs suomalainen äesvalmistaja on kehittänyt työsyvyyden mittausmenetelmän, jossa ultraäänianturi mittaa äkeen ja maanpinnan välistä etäisyyttä suoraan ilman mittasuksea tai -pyörää. Valmistajan mukaan mittauksen tarkkuus on $\pm 1 \mathrm{~cm}$. Tässä menetelmässä pystyssä törröttävä olki voi hämätä ultraäänianturia. Raper ja Grift (2002) osoittivat, että myös laserilla pystyy mittaamaan syvyyttä maassa. Tuossa tutkimuksessa laseria käytettiin mittaamaan muokkauksen vaikutuksia maassa, mutta menetelmä toimisi todennäköisesti myös peltoviljelykoneiden työsyvyyden mittauksessa.

Tämän tutkimuksen tavoitteena oli kehittää tarkka vantaiden työsyvyyden mittausjärjestelmä, kalibroida se ja yhdistää se paikkatietojärjestelmään siten, että kylvetystä pellosta voidaan piirtää työsyvyyskartta. Pellon muita ominaisuuksia mittaamalla voidaan sitten päätellä, miksi työsyvyys ei ole pysynyt asetusarvossaan jossain tietyssä kohtaa.

Tarvittavaksi mittausalueeksi arvioitiin $150 \mathrm{~mm}$. Tästä saadaan esimerkiksi mittausalue, joka ulottuu $120 \mathrm{~mm}$ maan pinnan alapuolelle ja $30 \mathrm{~mm}$ yläpuolelle. Korkeammalla tai syvemmällä tapahtuvat tapahtumat eivät ole kovin kiinnostavia. Mittausjärjestelmän tarkkuusvaatimukseksi asetettiin $\pm 5 \mathrm{~mm}$ tällä alueella.

\section{Aineisto ja menetelmät}

Tässä tutkimuksessa päädyttiin käyttämään tuntoelimenä etureunastaan saranoitua mittasuksea, jota painatetaan säädettävällä jousella maata vasten (kuva 1). Sen oletettiin seuraavan tarkemmin maan pintaa kuin mittapyörän, ja toisaalta myös vantaiston ahtaus rajoitti mittapyörän käyttöä. Pellolla tehdyissä esikokeissa mittasuksi näyttikin seuraavan maanpintaa tarkasti. Anturiksi valittiin Positekkulmanmittausanturi (P502.30AJ) sen hyvän tarkkuuden vuoksi ja koska sen kestävyys arvioitiin parhaaksi esimerkiksi kiveenajotilanteessa. Esimerkiksi LVDT-anturi ei kestä kovin suuria vääntövoimia sivusuunnassa. Kylvökoneeseen asennettiin mittasukset kaikkiaan kolmeen eri vantaaseen. Katsottiin, että on järkevämpää mitata yksittäisten vantaiden työsyvyyksiä, kuin yrittää arvioida koko kylvökoneen työsyvyyttä. 
Kulmanmittausanturit kytkettiin mittaustraktorissa olleeseen tietokoneeseen Keithley-mittauskortin välityksellä. Mittaustaajuudeksi asetettiin $15 \mathrm{~Hz}$. Työsyvyysinformaation kytkemiseksi paikkatietojärjestelmään kylvötraktoriin asennettiin Trimble Pro XR DGPS-paikanninlaite. Sen tarkkuuden ilmoitetaan olevan parempi kuin $\pm 75 \mathrm{~cm}$ (Trimble 1996). Laitteen mittaustaajuus on $1 \mathrm{~Hz}$.
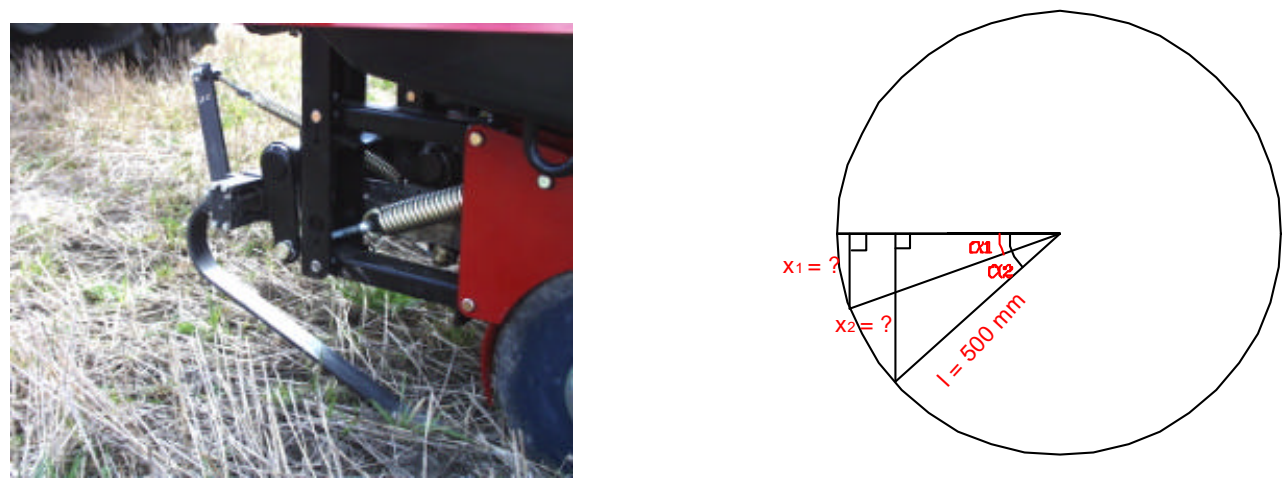

Kuva 1. Vasemmalla mittasuksi mittaa yksittäisen kiekkovantaan työsyvyyttä. Oikealla mittasuksen liike kaavakuvana. Kulmanmittausanturi mittaa kulmaa $\alpha$, josta lasketaan työsyvyys x kaavalla $\mathrm{x}=\mathrm{L} * \sin \alpha$.

Kulmanmittausanturi mittaa jännitteenmuutosta, joka oli ensin muunnettava kulmanmuutokseksi ja lopulta korkeudenmuutokseksi. Tähän käytettiin apuna kulmanmittausanturin kalibrointitodistuksessa olleita vakioarvoja ja geometriaa kuvasta 1. Lopullinen muunnosyhtälö jännitteestä työsyvyydeksi sai seuraavan muodon:

$$
\mathrm{x}=\mathrm{L} * \sin (43.3-((\mathrm{U}-2.504) / 0.143))-90
$$

jossa

$$
\begin{aligned}
& \mathrm{x}=\text { työsyvyys }(\mathrm{mm}) \\
& \mathrm{L}=\text { mittasuksen pituus } \\
& \mathrm{U}=\text { anturin mittaama jännite }
\end{aligned}
$$

Kalibrointien tarkoituksena oli selvittää, kuinka tarkasti kulmanmittausanturi, mittasuksi ja mittaustietokone toimivat yhdessä. Staattisessa kalibroinnissa $150 \mathrm{~mm}: \mathrm{n}$ mittausalue mentiin $10 \mathrm{~mm}: \mathrm{n}$ portain lävitse ja katsottiin, paljonko mittaustietokone näyttää milläkin portaalla. Hystereesin selvittämiseksi sama alue mentiin läpi myös toiseen suuntaan.

Dynaamista kalibrointia varten pyrittiin löytämään koejärjestely, joka matkii pellolla tapahtuvia äkillisiä mittasuksen liikkeitä, mutta on toisaalta määriteltävissä tarkasti matemaattisesti. Tätä varten päädyttiin rakentamaan kalibrointipenkki, jossa sähkömoottori käytti epäkeskon välityksellä edestakaisin liikkuvaa mäntää. Männän liike oli siten ajan funktiona siniaallon muotoista. Taajuusmuuntimen ja mekaanisen välityksen avulla mäntää ja sen päähän kytkettyä mittasuksea voitiin liikuttaa edestakaisin $1-5 \mathrm{~Hz}: n$ taajuuksilla. Männän iskunpituutta voitiin säätää välillä $0-160 \mathrm{~mm}$.

Dynaamisissa kalibroinneissa männän iskunpituudeksi valittiin $2,10,50,100$ ja $150 \mathrm{~mm}$, sekä taajuuksiksi 1, 3 ja $5 \mathrm{~Hz}$. Yhteensä tästä tuli 15 erilaista testiajoa. Männän taajuudet säädettiin oikeiksi optisen kierroslukumittarin avulla. Kalibrointi olisi ollut hyvä tehdä vielä suuremmillakin taajuuksilla, sillä jos kylvötraktorin ajonopeus on $3 \mathrm{~m} / \mathrm{s}$, niin $5 \mathrm{~Hz}$ taajuudella mittauspisteiden väliksi tulee $0,6 \mathrm{~m}$. Tämä ei ole kovin tiheä näytetaajuus pellossa olevia kokkareita ja uria ajatellen, mutta ehkä riittävän tiheä keskimääräisen työsyvyyden mittaamiseen. Suurempia taajuuksia ei kuitenkaan käytetty, koska mittapenkki olisi todennäköisesti rikkoutunut nopeilla taajuuksilla.

\section{Tulokset ja tulosten tarkastelu Staattinen kalibrointi}

Mittausjärjestelmän lineaarisuus havaittiin staattisessa kalibroinnissa hyväksi (kuva 2). Regressioanalyysin selitysaste $\left(\mathrm{R}^{2}\right)$ oli lähes 1 . Suurin epätarkkuus havaittiin mittausalueen molemmissa päissä (max. $\pm 4.8 \mathrm{~mm}$ ), koska kulmanmittausanturi ei toimi siellä enää lineaarisesti. Mittausalueen keskivaiheilla $(170-300 \mathrm{~mm})$ epätarkkuus oli $< \pm 2 \mathrm{~mm}$. Tarkkuus koko mittausalueelle $(150 \mathrm{~mm})$ oli siis $< \pm 5 \mathrm{~mm}$ tai $< \pm 3 \%$. Kuvan 2 mukaan systeemin hystereesi näytti olevan hyvin pieni. 


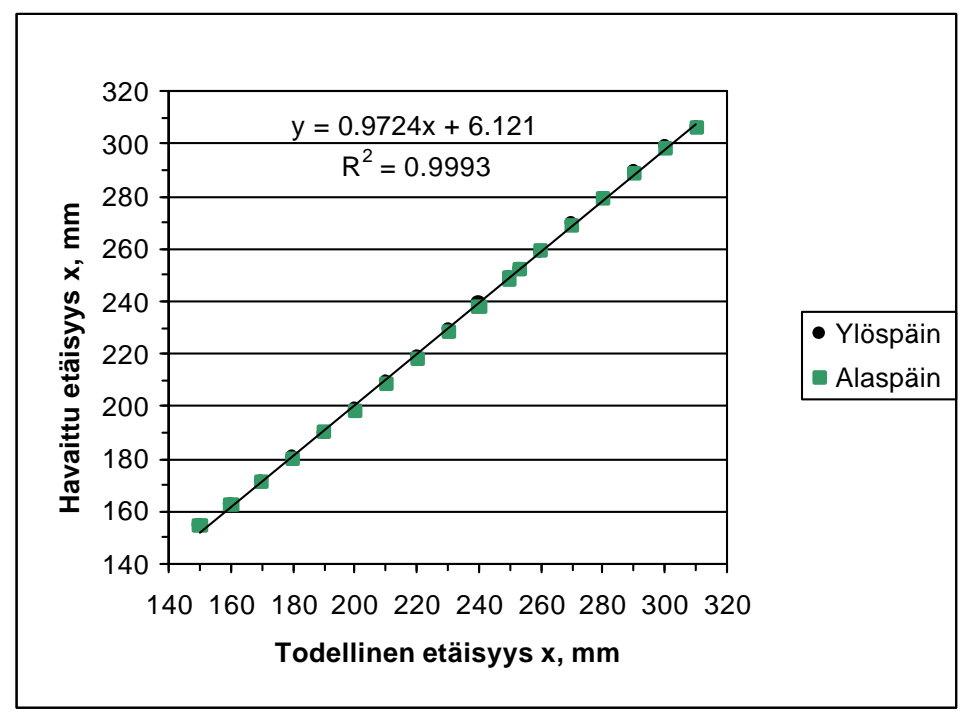

Kuva 2. Staattisen kalibroinnin tulokset. "Todellinen etäisyys x" mitattiin millimetrimitalla ja "Havaittu etäisyys x" on mittaustietokoneen näyttämä etäisyys.

\section{Dynaaminen kalibrointi}

Dynaamisten kalibrointien tarkoituksena oli selvittää, kuinka tarkasti mittausjärjestelmä kykenee seuraamaan äkillisiä muutoksia, eli kuinka paljon havaitut arvot poikkeavat ideaalisesta siniaallosta $(y=\sin (x))$. Kuvassa 3 on esimerkki näistä vertailuista, joissa mitattu ja ideaalinen siniaalto piirrettiin samaan koordinaatistoon. Kun taajuutta kasvatettiin tai iskunpituutta pienennettiin, mitattu arvo ei enää seurannut ideaalista siniaaltoa yhtä tarkasti kuin kuvassa 3. Valtaosassa mittauksia seuraavuus oli kuitenkin hyvä.

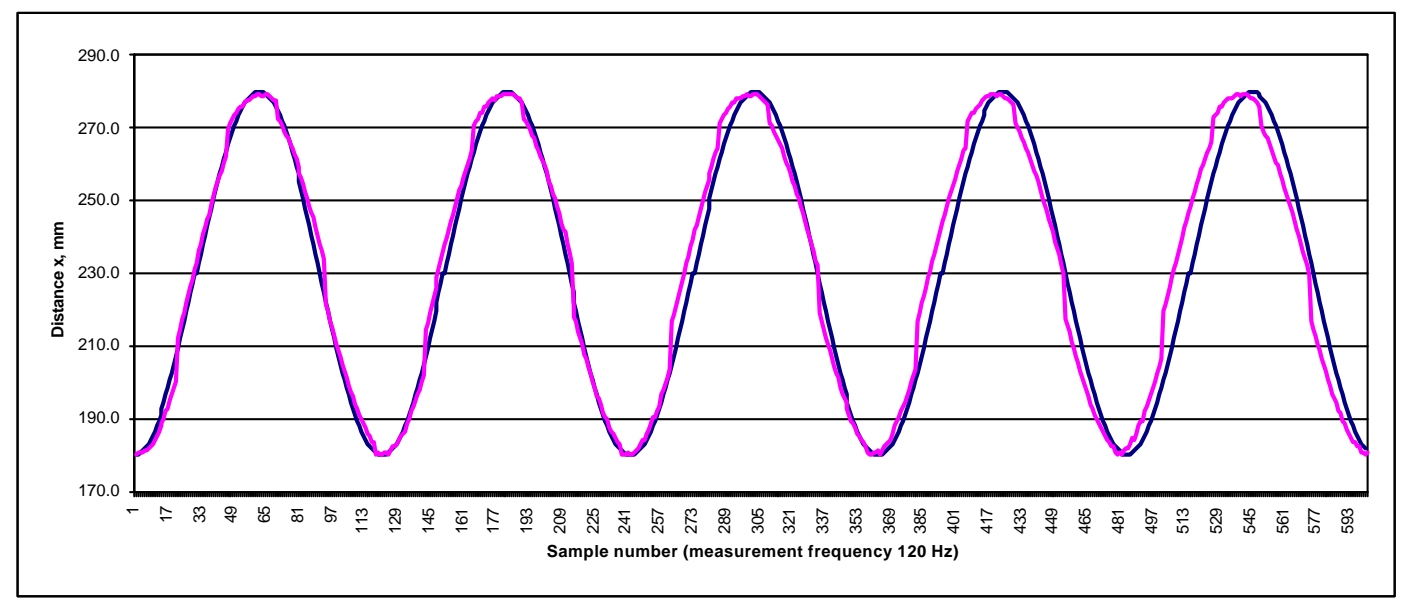

Kuva 3. Mitattu etäisyys ja todellinen etäisyys samassa kuvassa. Männän taajuus oli tässä $1 \mathrm{~Hz}$ (1 isku sekunnissa) ja iskun pituus $100 \mathrm{~mm}$.

Taulukkoon 1 on koottu dynaamisissa kalibroinneissa käytetyt kalibrointimännän liiketaajuudet, iskunpituudet (amplitudit) ja suurimmat havaitut poikkeamat siniaallon käännekohdissa eli huipuissa. Lisäksi siihen on laskettu havaintojen keskimääräinen virhe koko mittausalueelta. Tämä luku on keskiarvo seuraavalla kaavalla lasketuista yksittäisistä virheistä:

$$
\text { Virhe } \%=100 \% *\left(\mathrm{x}_{\text {mitattu }}-\mathrm{x}_{\text {todellinen }}\right) / \text { Amplitudi }
$$

Taulukosta 1 voidaan nähdä, että virheet mittasuksen käännekohdissa yleensä kasvoivat, kun taajuutta tai iskunpituutta kasvatettiin. Sen sijaan keskimääräinen suhteellinen virhe oli yleensä suurin pienillä iskunpituuksilla, koska mittaussysteemin erottelukyky oli rajallinen (luokkaa $2 \mathrm{~mm}$ ). Suurimmat keskimääräiset virheet havaittiin $3 \mathrm{~Hz}: n$ taajuudella. Tällöin kalibrointipenkki ja mittasuksi alkoivat värähdellä, mikä häiritsi mittausta. Kaikissa mittauksissa ei nyt enää päästy asetettuun 
tarkkuustavoitteeseen $( \pm 5 \mathrm{~mm})$, ainakaan mittasuksen käännekohdissa. Noissa käännekohdissa mittasuksen liikesuunta vaihtui erittäin nopeasti ja ne eivät ole sen takia kovin tärkeitä työsyvyyden mittauksessa, jossa halutaan saada pidemmän matkan keskiarvo. Hyvä ominaisuus mittausjärjestelmässä oli se, että se palautui aina näyttämään samaa tasoa, kun kalibrointipenkin liike pysäytettiin, ts. ryömintää ei esiintynyt.

Taulukko 1. Dynaamisissa kalibroinneissa käytetyt amplitudi- ja taajuuskombinaatiot, sekä mittaustulokset. Tulokset on saatu vertaamalla mitattuja arvoja ideaalisiin siniaaltoihin.

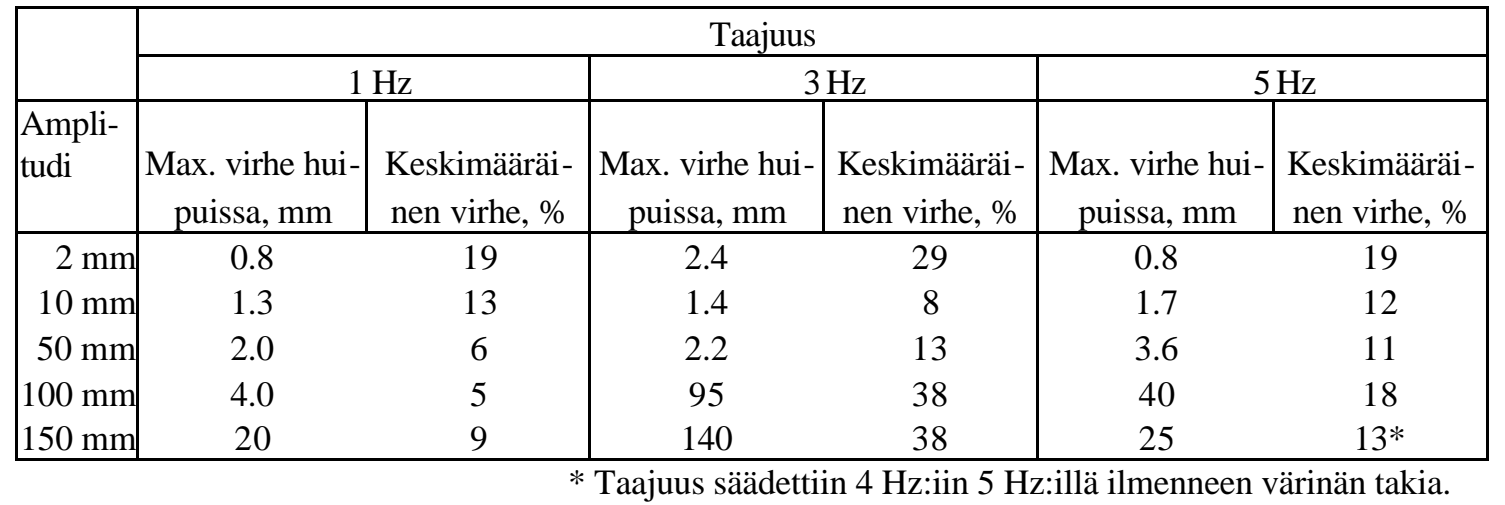

\section{Johtopäätökset}

Staattisen kalibroinnin tulokset korreloivat hyvin todellisiin etäisyysarvoihin. Staattinen kalibrointi on toistettu lukuisia kertoja mittasuksien ollessa paikallaan kylvökoneessa ja aina tulokset ovat olleet yhtä hyviä. Kulmanmittausanturin paras tarkkuus on mittausalueen keskialueella, joten kyseinen anturi on tärkeää asentaa siten, ettei käytettävä mittausalue ylitä \pm 9 astetta.

Dynaamisissa kalibroinneissa havaitut virheet olivat selvästi suurempia kuin staattisessa kalibroinnissa, mutta tarkkuusvaatimus $( \pm 5 \mathrm{~mm})$ ja mitta-aluevaatimus $(150 \mathrm{~mm})$ täyttyivät useimmissa tapauksissa. Dynaamiset kalibroinnit osoittivat, että mittaustiedon suodattaminen voi olla tarpeellista esimerkiksi liukuvan keskiarvon avulla, koska varsinkin suuremmilla taajuuksilla anturi antoi joskus selvästi virheellisiä yksittäisiä arvoja.

Saattaa olla, että mittasuksi ei pysty seuraamaan täsmällisesti kaikkia maanpinnan muutoksia, esimerkiksi pieniä poikittaisia uria tai maakokkareita. Nämä eivät ole kuitenkaan olennaisia, koska tavoitteena on mitata työsyvyyttä pidemmän matkan keskiarvona. Todennäköisesti mittasuksi hieman yliarvioi maanpinnan korkeutta, koska se pystyy huomioimaan korkeimmat kohdat pinnasta, mutta ei pysty pudottautumaan kaikkien matalien kohtien pohjalle. Tähän suuntaan viittaavat myös menetelmän avulla piirretyt kylvösyvyyskartat: mittausjärjestelmä on näyttänyt yleensä $1-2 \mathrm{~cm}$ syvempää kylvösyvyyttä, kuin mitä samoista paikoista käsin mitatut kylvösyvyydet ovat olleet. Lohkon sisäinen vaihtelu näkyy kylvösyvyyskartoista hyvin.

\section{Kirjallisuus}

Ahokas, J. 1994. The effect of ground profile and plough gauge wheel on ploughing work with a mounted plough. Vakolan tutkimusselostus nro 69. Agricultural Research Centre of Finland. Institute of Agricultural Engineering (VAKOLA). (Diss. : Espoo : Helsinki University of Technology, 1995). 90 p.

Arrivo, A. \& Di Renzo, G. C. 1998. Trailed unit for testing implements under field conditions. Journal of Agricultural Engineering Research 71: 19-24.

Gebresenbet, G. \& Jönsson, H. 1992. Performances of seed drill coulters in relation to speed, depth and rake angles. Journal of Agricultural Engineering Research 52: 121-145.

Raper, R.L. \& Grift, T.E. 2002. Land laser. Alternative measuring device records tillage effects. ASAE, Resource: 4/9: 7-8.

Sögaard, H.T. 1998. Automatic control of a finger weeder with respect to the harrowing intensity at varying soil structures. Journal of Agricultural Engineering Research 70: 157-163.

Trimble. 1996. Pro XR Receiver Manual. Trimble navigation limited surveying \& mapping division. Sunnyvale, USA. 